EPJ Web of Conferences 110, 01060 (2016)

DOI: $10.1051 /$ epjconf/201611001060

(C) Owned by the authors, published by EDP Sciences, 2016

\title{
EFFECT OF THE HEAT FLUX DENSITY ON THE EVAPORATION RATE OF A DISTILLED WATER DROP
}

\author{
Konstantin Ponomarev ${ }^{1,}$, Evgeniya Orlova ${ }^{1}$, Dmitry Feoktistov ${ }^{1}$ \\ ${ }^{1}$ National Research Tomsk Polytechnic University, 634050, Tomsk, Russia
}

\begin{abstract}
This paper presents the experimental dependence of the evaporation rate of a nondeaerated distilled water drop from the heat flux density on the surfaces of non-ferrous metals (copper and brass). A drop was placed on a heated substrate by electronic dosing device. To obtain drop profile we use a shadow optical system; drop symmetry was controlled by a high-speed video camera. It was found that the evaporation rate of a drop on a copper substrate is greater than on a brass. The evaporation rate increases intensively with raising volume of a drop. Calculated values of the heat flux density and the corresponding evaporation rates are presented in this work. The evaporation rate is found to increase intensively on the brass substrate with raising the heat flux density.
\end{abstract}

\section{Introduction}

The evaporation rate is one of the factors defining the intensity of heat exchange surface cooling. This rate must be sufficient to prevent the transition from drop to film boiling, which is accompanied by a decrease in the intensity of a heat sink [1]. The transition from one boiling regime to another is determined by the heat flux density through a heated surface and its physical properties (in particular, wettability), physical properties of liquid and in general hydrodynamic flow regime. The Leidenfrost effect can be seen at high evaporation rates, when a layer of vapor is formed between a drop and a wall. This layer of vapor has a low thermal conductivity, resulting in decrease of heat exchange coefficient than tenfold. During evaporation of liquid drops on the highly-heated surfaces, this phenomenon leads to the destruction of the walls of heat exchangers because of the reduction of heat removal.

The evaporation rate depends on the temperature and material of a surface, composition of a liquid, drop volume, temperature and pressure of the ambient, velocity of the air over the liquid surface, the heat flux density [2,3]. It is known [4] that if the surface temperature is less than the saturation temperature of the liquid, the evaporation rate increases. But nowadays the effect of physical properties of the heat transfer wall and its thickness on the intensity of heat transfer is an open problem.

Studying the influence of all these factors on the evaporation rate of a drop will provide physical mechanisms, which may be used in the development of high-intensity heat exchangers applied as evaporators, cooling systems micro-equipment and etc.

The purpose of this work is to study the effect of the evaporation rate of distilled water drops on the heat flux density.

\footnotetext{
${ }^{a}$ Corresponding author: kop.tpu@gmail.com
} 


\section{Experimental procedure}

Experimental studies were carried out on the setup [5,6] using the equipment of the shadow optical system (Fig. 1).

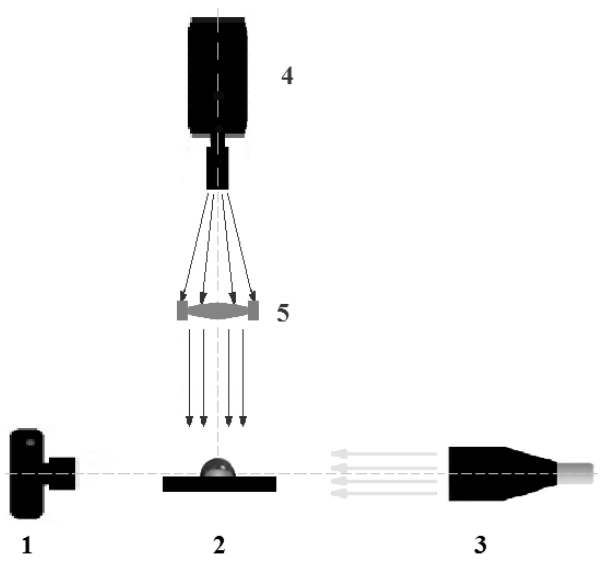

Figure 1. Schematic of the experimental setup: 1 - photographic camera, 2 - substrate with a drop, 3 - source of plane-parallel light, 4 - high-speed video camera, 5 - condensing lens.

The experimental method is described in detail in [6].

A drop was placed on a heated substrate with diameter of $54 \mathrm{~mm}$ and $4 \mathrm{~mm}$ thick by electronic dosing device Single Channel Pipette (Thermo Scientific).

The evaporation rate is calculated by using the following equation:

$$
E S=\frac{\left(V_{0}\right)}{t}, \frac{\mu l}{s},
$$

where $V_{0}$ is initial volume of a drop, $\mu 1$;

$t$ is total time of evaporation, s.

The heat exchange with the environment and the influence of boundary effects has been neglected. The heat transfer is assumed to be mainly by thermal conductivity:

$$
q=\frac{\Delta t}{\frac{\delta}{\lambda}} \cdot 10^{-6}, \frac{W}{m m^{2}}
$$

where $\Delta t$ is temperature difference between the bottom and the top side of the substrate, ${ }^{\circ} C$;

$\delta$ is thickness of the substrate, $\mathrm{m}$;

$\lambda$ is thermal conductivity coefficient, $\frac{W}{m \cdot{ }^{o} \mathrm{C}}$.

The values of main influencing parameters are presented in Table 1.

Table 1. The main influencing parameters.

\begin{tabular}{|c|c|}
\hline Parameter & Parameter value \\
\hline Investigated liquid & nondeaerated distilled water \\
\hline Material of the substrate & copper, brass \\
\hline Liquid volume, $\mu 1$ & $10,20,30,40,50,60$ \\
\hline
\end{tabular}




\section{Results and discussion}

It has been found that the evaporation rate of a drop on the copper substrate is greater than on the brass. This is due to the fact that the thermal conductivity of the copper is greater than conductivity of the brass. Hence the heat flux density is greater for the copper at the same temperatures of heating. A drop on this surface is warming faster; and the numbers of molecules with sufficient kinetic energy to overcome the forces of intermolecular attraction increases. Therefore, the evaporation rate of a drop on the copper is greater.

Dependences of the evaporation rate of a drop from the heat flux density are presented in Fig. 2.

(a)

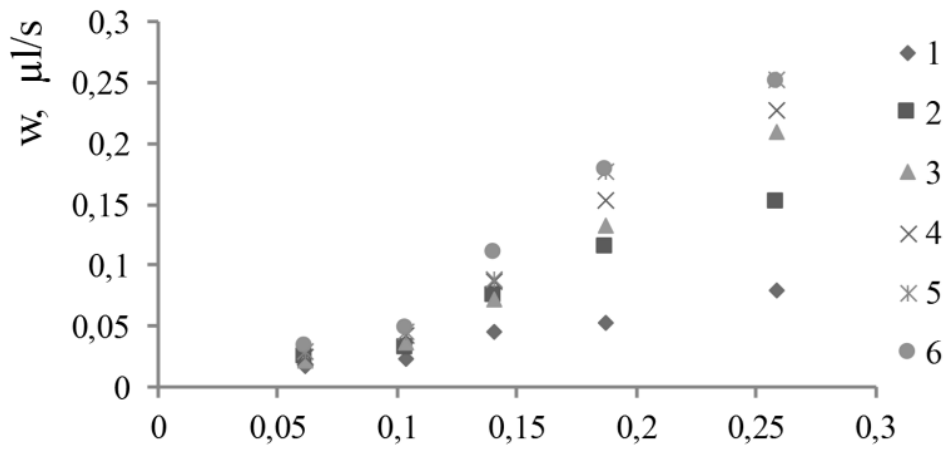

$\mathrm{q}, \mathrm{W} / \mathrm{mm}^{2}$

(b)

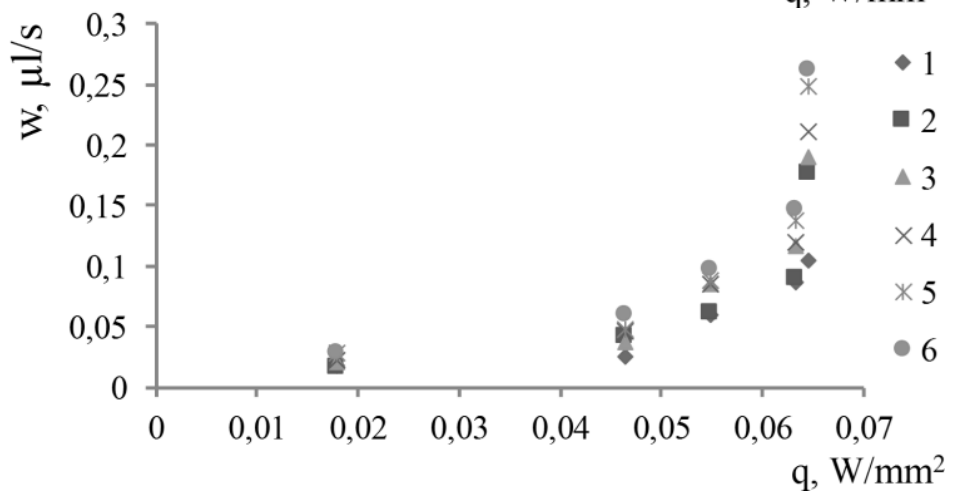

Figure 2. Evaporation rate of a drop versus heat flux density: (a) copper substrate, (b) brass substrate. Drop volume: $1-10 \mu \mathrm{l} ; 2-20 \mu \mathrm{l} ; 3-30 \mu \mathrm{l} ; 4-40 \mu \mathrm{l} ; 5-50 \mu \mathrm{l} ; 6-60 \mu \mathrm{l}$.

Obtained dependences of the evaporation rate from the heat flux density are similar to the dependences obtained in [7], where the change of mass evaporation rate of water drops on copper, aluminum, brass and bronze substrates in the temperature range from 25 to $75{ }^{\circ} \mathrm{C}$ is presented. The values of evaporation rates [7] are five time less in comparison with our results. It results from the thickness of the substrates studied (2.5 times thicker) and also a nanoscale coating on the substrate surface.

It has been found that the evaporation rate increases intensively at increasing the drop volume.

Increase of the heat flux density from $0.061 \mathrm{~W} / \mathrm{mm}^{2}$ to $0.258 \mathrm{~W} / \mathrm{mm}^{2}$ on the copper substrate led to an increase in the evaporation rate of $0.06 \div 0.13 \mu \mathrm{l} / \mathrm{s}$ for a drop volume of $10 \div 20 \mu \mathrm{l}$, and $0.19 \div 0.22 \mu \mathrm{l} / \mathrm{s}$ for a drop volume of $30 \div 60 \mu \mathrm{l}$. At raising the heat flux density from $\mathrm{q}=0.018 \mathrm{~W} / \mathrm{mm}^{2}$ to $\mathrm{q}=0.065 \mathrm{~W} / \mathrm{mm}^{2}$ the evaporation rate increases by $0.09 \mu \mathrm{l} / \mathrm{s}$ for a drop volume of $10 \mu \mathrm{l}$ and $0.16 \div 0.23 \mu \mathrm{l} / \mathrm{s}$ for large volumes. 
For small drop volumes $(10 \div 20 \mu \mathrm{l})$ with rise of the heat flux density the evaporation rate increases by $1.5 \div 3$ times slower than at high volumes on the copper substrate, on the brass substrate - by $1.5 \div 6$ times.

A gradual increase of the temperature by $10{ }^{\circ} \mathrm{C}$ on the copper substrate is accompanied by a steady increase in the heat flux density by $0.04 \mathrm{~W} / \mathrm{mm}^{2}$. There is only one exception at the temperature of $80{ }^{\circ} \mathrm{C}$, when an increase equals to $0.07 \mathrm{~W} / \mathrm{mm}^{2}$. The heat flux density increases nonuniformly from the largest value $0.03 \mathrm{~W} / \mathrm{mm}^{2}$ to the lowest for the brass substrate under the same conditions.

Therefore, new experimental data on the dependence of the evaporation rate of liquid from the heat flux density on copper and brass surfaces have been obtained. The evaporation rate increases with increasing the heat flux density because of raising the number of molecules of a liquid with sufficient value of kinetic energy to overcome the attraction of neighboring molecules and move to the vapor.

Obtained dependences were different for the copper and brass substrates; the evaporation rate increases intensively on the brass substrate. The drops were not in the spheroidal state and spreads over the heated surface, i.e. wetted it.

The evaporation rate increases intensively with increasing the drop volume due to raising the surface area of liquid.

The work was held within the research state assignment "Science" №13.1339.2014/K (Code of Federal Target Scientific and Technical Program 2.1410.2014).

\section{References}

1. V. E. Nakoryakov, S. Ya. Misyura, S. L. Elistratov, Int. J. Heat Mass Transfer, 55, 6609 (2012)

2. H. Y. Erbil, Adv. Colloid Interface Sci., 170, 67 (2012)

3. E. Gatapova, A. Semenov, D. Zaitsev, O. Kabov, Colloid Surf. A, 441, 776 (2014)

4. E.V. Anokhina, Technical Physics, 55, 8 (2010)

5. K. A. Batischeva, E. G. Orlova, D. V. Feoktistov, MATEC Web of Conferences, 19, 1 (2014)

6. E. G. Orlova, G. V. Kuznetsov, D. V. Feoktistov, EPJ Web of Conferences, 76, 1 (2014)

7. B. Sobac, D. Brutin, Phys. Rev. E, 86, 021602 (2012) 